\title{
Risk factors for TB and HIV coinfection in Scotland, 2001 to 2010
}

E McDonald ${ }^{1}$, Alison Smith-Palmer (alison.smith-palmer@nhs.net) ${ }^{1}$, L A Wallace ${ }^{1}, 0$ Blatchford ${ }^{1}$

1. Health Protection Scotland, Glasgow, United Kingdom

Citation style for this article:

McDonald E, Smith-Palmer A, Wallace LA, Blatchford O. Risk factors for TB and HIV coinfection in Scotland, 2001 to 2010. Euro Surveill. 2015;20(11):pii=21067.

Available online: http://www.eurosurveillance.org/ViewArticle.aspx?Articleld=21067

The number of patients with tuberculosis (TB) increased steadily in Scotland between 2005 and 2010. Human immunodeficiency virus (HIV) infection has been a contributory factor to increases in TB in a number of comparable industrialised countries. This study investigated the extent of, and risk factors for, TB and HIV coinfection in Scotland from 2001 to 2010. Patients with TB in the national TB database were linked to those in the national HIV database using probabilistic data linkage. Patient records were anonymised to maintain confidentiality. From 2001 to 2010, 106/4,097 (2.6\%, 95\% Cl: 2.1 to 3.1) TB patients matched with HIV patients, equating to a 10-year incidence of 2.1 cases per million population. Patients with both TB and HIV were more often born outside the United Kingdom, were of black African ethnicity, had refugee status and had extra-thoracic lymph node involvement or cryptic/disseminated TB disease. Individuals with TB and HIV coinfection were younger and symptomatic for a shorter time before their diagnosis of TB, compared with TB patients without HIV. TB and HIV coinfection was relatively uncommon in Scotland in the study period. Clinicians should recognise the potential for HIV infection among TB patients and the importance of offering an HIV test to all TB patients.

\section{Introduction}

Human immunodeficiency virus (HIV) infection and associated immunosuppression is a major risk factor for the development of active tuberculosis (TB), either through acquisition of new infection or re-activation of latent TB [1]. The incidence of tuberculosis is known to be increased in immunocompromised individuals. Globally, considerable progress has been made to address the TB/HIV co-epidemic; however, global-level targets for HIV testing among TB patients and provision of antiretroviral therapy to those who are HIV positive have not been reached [2]. In Scotland, TB is a statutory notifiable disease [3]. In addition, enhanced surveillance of TB has been undertaken in Scotland since 2000 through the Enhanced Surveillance of Mycobacterial Infections scheme [4]. Enhanced surveillance data on TB provide information on the numbers, distribution and characteristics of TB cases, drug-resistance patterns and treatment outcomes. This surveillance supports the early identification and treatment of cases and enables the identification of high-risk populations. Annual case numbers increased steadily in Scotland, from 365 cases in 2005 (7.2 per 100,000 population) to 508 cases in 2010 (9.6 per 100,000), mainly among persons born outside the United Kingdom (UK) [5]. More recent data from 2012 show that 408 TB cases were reported in Scotland, equating to an annual incidence of 7.7 cases per 100,000 population [5].

HIV infection is not a statutorily notifiable in Scotland but HIV surveillance has been undertaken in the country since 1981 through voluntary reporting of new HIV diagnoses by laboratories, acquired immunodeficiency syndrome (AIDS) diagnoses from clinicians, and deaths due to HIV infection or AIDS reported to the General Register Office for Scotland. Records of HIV or AIDS diagnoses, and HIV/AIDS-related deaths that are regarded as relating to the same individual are merged to create one record [6]. Since 1985, there has been a mean of 241 cases (standard deviation (SD): 84.3 ) of HIV reported in Scotland each year increasing initially from 1984 to 1987 , with a mean of 281 cases per year (SD: 29.4), then again from 2002 to 2007, with a mean of 338 cases per year (SD: 58.3 ) [7].

Current national guidance recommends that all TB cases be offered an HIV test [8-10]. In addition, the TB action plan for Scotland [11] recommends that the HIV status of all TB cases be known as this is a requirement for annual reporting to the European Tuberculosis Surveillance Network at the European Centre for Disease Prevention and Control (ECDC) [12]. Despite these recommendations, the HIV status of TB cases remains unknown at a national level in Scotland as these data are not routinely collected or linked.

We used record linkage from 1984 to 2010 to investigate the extent of TB and HIV coinfection and identify risk factors for TB and HIV coinfection in Scotland.

\section{Methods}

Reports on 4,097 patients diagnosed with TB in Scotland from 2001 to 2010 were extracted from the Enhanced Surveillance of Mycobacterial Infections 


\section{FIGURE 1}

Number of cases and incidence of tuberculosis and human immunodeficiency virus coinfection in Scotland, by year of tuberculosis diagnosis, 2001-10 $(\mathrm{n}=106)$

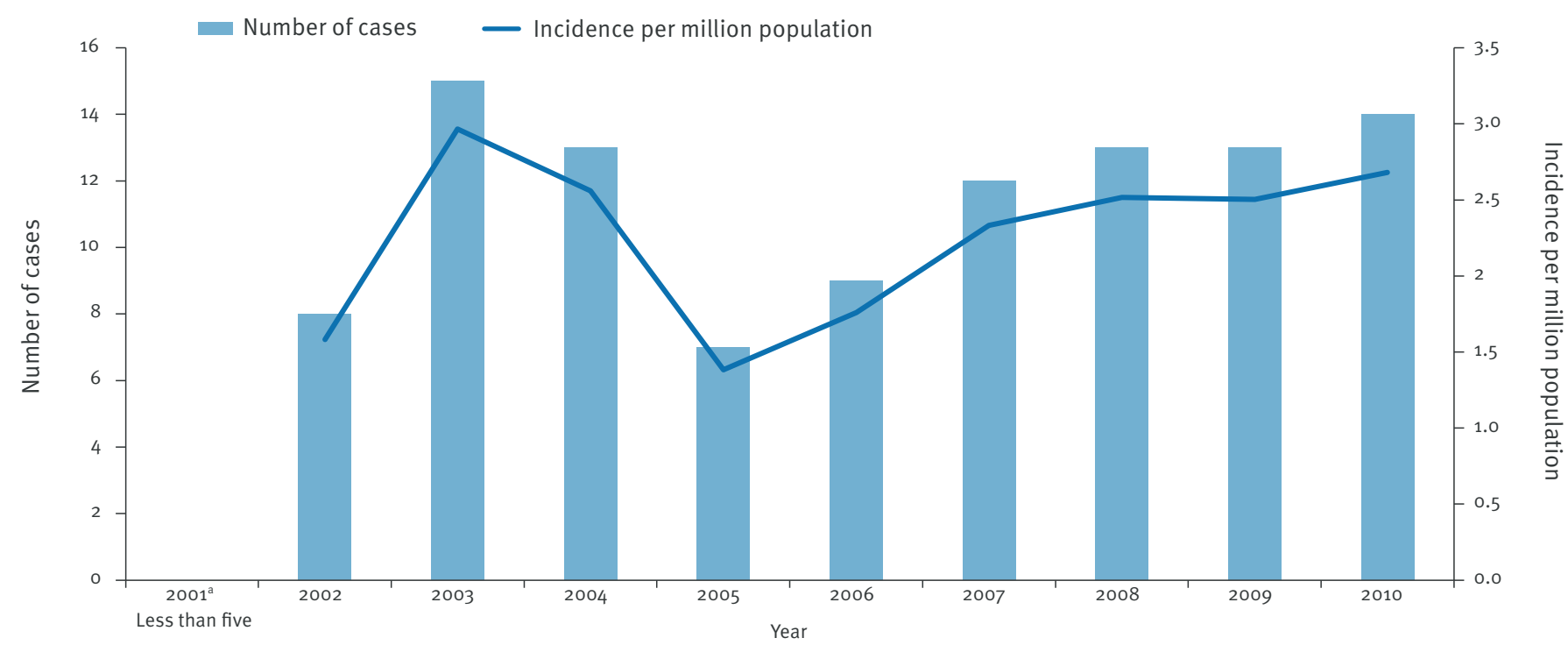

a Data withheld due to numbers of less than five, to reduce potential for deductive disclosure.

\section{FIGURE 2}

Age group (age at tuberculosis diagnosis) and sex of tuberculosis and human immunodeficiency virus coinfected cases in Scotland, 2001-10 $(\mathrm{n}=106)$

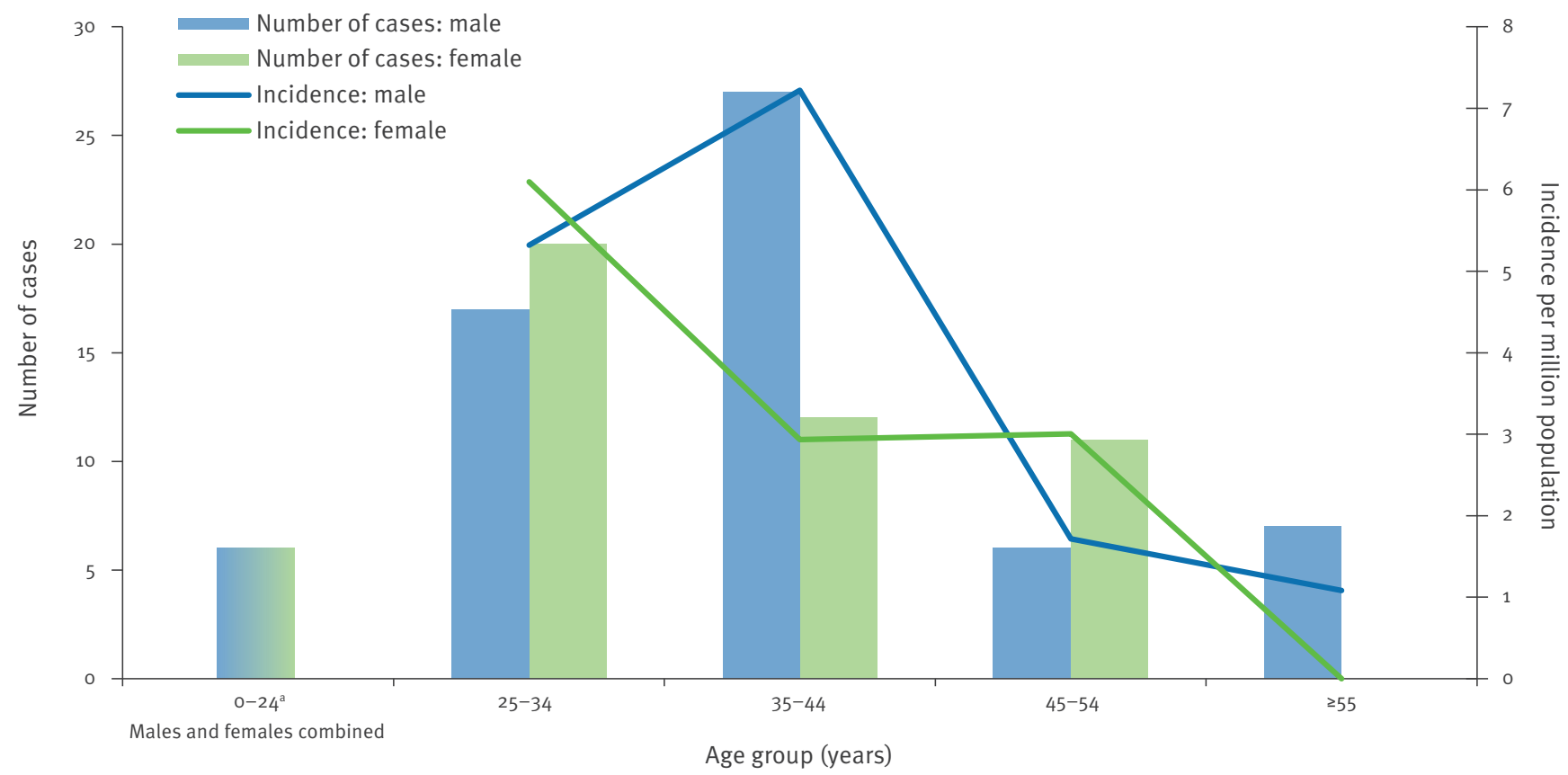

a Data combined due to numbers of less than five, to reduce potential for deductive disclosure. 
database. These named patient data were then replaced by a Soundex code [13], i.e. replacing surnames by their initial letter followed by a three-digit coding of subsequent letters.

The HIV database contains Soundex-coded data for 6,790 patients with HIV antibody positive results in Scotland from 1981 to 2010 The anonymised TB patients were linked to the anonymised HIV patients using probabilistic data linkage $[14,15]$, thus maintaining patient confidentiality. TB and HIV coinfections were assigned a notification year by the year of their TB diagnosis.

Coinfected cases after 2010 could not be included in our analysis due to the time needed to obtain followup and outcome data (data collected 12 months after diagnosis) as well as the time needed to validate, carry out the linkage and analysis of the data.

Statistical analysis was performed in SPSS version 21. Characteristics of TB cases and TB and HIV coinfected cases were compared using chi-square test, Fisher's exact test, t-test or the Mann-Whitney test (depending on the nature of the variable and the sample size). Logistic regression was performed to investigate the association between the number of coinfected cases and the predictor variables, e.g. ethnicity, refugee status.

\section{Results}

\section{Case numbers and trends}

From 2001 to 2010, 4,097 tuberculosis cases were reported to Health Protection Scotland, of which 106 (2.6\%; 95\% confidence interval $(\mathrm{Cl})$ : 2.1-3.1) were matched to an individual on the HIV database, equating to a 10-year incidence of 2.1 cases per million population (95\% Cl: 1.7-2.5 per million population). There was a peak in the number of TB and HIV coinfections in
2003, when 15 patients (15/367; 4.1\%; 3.0 per million population) were reported (Figure 1). However, there were no statistically significant differences in the proportion of TB cases with HIV infection or the incidence of TB and HIV coinfections from 2001 to 2010.

\section{Age and sex distribution}

The most common age group of TB and HIV coinfection was $25-44$ years $(77 / 106 ; 73 \%)$ and $58 \%$ of cases $(62 / 106)$ were male (Figure 2$)$. The mean age of cases was 37 years. Coinfected individuals were aged a mean of 8.8 years less than that of TB patients without HIV infection $(p<0.00001)$.

\section{Site of TB}

The majority presented with pulmonary TB (69/106; $65 \%$ ). Our analysis showed that having TB and HIV coinfection was associated with an increased likelihood of pulmonary TB (odds ratio (OR): 2.2 (95\% Cl: 1.3-3.8), $p=0.004)$, extra-thoracic lymph node involvement (OR: 3.8 (95\%: Cl 2.1-6.7), p<0.0001) or cryptic/ disseminated TB (OR: 5.7 (95\% Cl: 2.5-13.2), p<0.0001) when compared with TB cases without HIV. There were no other statistically significant differences in site of disease between TB cases and TB and HIV coinfected cases (Table).

Of the 76 TB and HIV coinfected patients with known TB drug sensitivities, less than five had drug-resistant TB. However, there was no significant difference in drug resistance rates between those with TB and those with TB and HIV coinfection.

\section{Ethnicity and country of birth}

The majority of coinfected patients were born outside the UK $(75 / 106 ; 71 \%)$. The mean time from entry into the UK until a TB diagnosis was 3.6 years, compared with 7.3 years in cases with TB alone (difference in mean of 3.7 years ( $95 \% \mathrm{Cl}: 2.7-4.8), \mathrm{p}<0.01)$.). The likelihood of

\section{TABLE}

Logistic regression analysis of risk factors associated with tuberculosis and human immunodeficiency virus coinfection in Scotland, 2001-10 $(\mathrm{n}=106)$

\begin{tabular}{|c|c|c|c|}
\hline Risk factor & Number of cases & Odds ratio $(95 \% \mathrm{Cl})$ & P value \\
\hline Pulmonary TB & 69 & $2.2(1.3-3.8)$ & 0.004 \\
\hline TB infection of extra-thoracic lymph node & 30 & $3.8(2.1-6.7)$ & $<0.0001$ \\
\hline Cryptic/disseminated TB disease & 8 & $5.7(2.5-13.2)$ & $<0.0001$ \\
\hline Black African ethnicity ${ }^{a}$ & 67 & $7.6(3.4-16.9)$ & $<0.0001$ \\
\hline White ethnicity ${ }^{\mathrm{a}}$ & 23 & $0.3(0.1-0.7)$ & 0.006 \\
\hline Refugee status $^{b}$ & 22 & $5.2(3.2-8.6)$ & $<0.0001$ \\
\hline History of BCG vaccination ${ }^{c}$ & 61 & $1.6(1.1-2.4)$ & 0.016 \\
\hline History of travel outside the UK for $\geq 2$ months $^{b, d, e}$ & 33 & $2.2(1.4-3.3)$ & $<0.0001$ \\
\hline
\end{tabular}

BCG: Bacillus Calmette-Guérin; $\mathrm{Cl}$ : confidence interval; TB: tuberculosis; UK: United Kingdom.

a Ethnicity data were missing for five cases.

b Risk factor data were missing for six cases.

BCG vaccination status was missing for 31 cases.

d In the two years preceding their TB diagnosis.

e Information on travel outside the UK missing for 20 cases. 
TB and HIV coinfection was almost eight-times higher among non-UK born TB cases (OR: 7.9 (95\% Cl: 4.514.4), $p<0.00001)$.

The majority of coinfected cases were of black African $(67 / 106 ; 63 \%)$ or white $(23 / 106 ; 22 \%)$ ethnicity, with very few from other ethnic groups. The likelihood of TB and HIV coinfection was higher among TB cases of black African ethnicity (OR: 7.6 (95\% Cl: 3.4.3-16.9), $\mathrm{p}<0.00001)$ and lower among those of white ethnicity (OR: 0.3 (95\% Cl: 0.1-0.7), $\mathrm{p}=0.006)$ when compared with those with TB alone (Table). Just over half of black African cases were female (37/67), but male cases were statistically significantly more common among those of non-black African ethnicity (28/34, p =0.002).

\section{Risk factors}

A total of $32 \%(34 / 106)$ had a reported risk factor for $\mathrm{TB}$, the most common of which was refugee status (22). Our analysis showed that being a refugee was independently associated with an increased likelihood of TB and HIV coinfection (OR: 5.2 (95\% CI: 3.2-8.6), $\mathrm{p}<0.0001)$ when compared with those with TB alone (Table).

The majority (61/75) were known to have had a BCG vaccination and approximately one third (33/86) had a history of travel outside of the UK for two months or more in the two years preceding their TB diagnosis. Very few cases (6/98) were known to have a previous diagnosis of TB. Logistic regression analysis showed that having a history of BCG vaccination (OR: 1.6 (95\% $\mathrm{Cl}: 1.1-2.4), p=0.016)$ and travel outside the UK for two months or more in the two years before their TB diagnosis (OR: 2.2 (95\% Cl: 1.4-3.3), $\mathrm{p}<0.001)$ were independently associated with an increased likelihood of TB and HIV coinfection when compared with those with TB alone (Table).

\section{Suspected source of HIV transmission}

Of the 106 coinfected cases, the main reported routes of HIV acquisition were via heterosexual intercourse $(84 / 106 ; 79 \%)$ and sex between men $(12 / 106 ; 11 \%)$. Those born outside the UK were more likely to have acquired HIV through heterosexual intercourse (OR 8.3 (95\% Cl: 2.2-30.2), $\mathrm{p}=0.002$ ), while those born in the UK were more likely to acquire HIV through sex with other men (OR: 13.1 (95\% Cl: 2.5-73.1), $\mathrm{p}=0.002$ ).

Individuals of black African ethnicity were more likely to have acquired HIV via heterosexual intercourse (OR: 24.0 (95\% Cl: 6.5-108.5), p<0.0001) while those of white ethnicity were more likely to have acquired their HIV infection through sex with other men (OR: 59.2 (95\% Cl: 8.4-1308.7), $p<0.00001$ ).

Eight of the 99 with transmission data were reported to have acquired HIV within Scotland, whereas the majority acquired the virus from outside the country $-71 / 99$ from Sub-Saharan Africa and 10/99 from south and south-east Asia. A total of 10/99 cases were reported to have acquired their HIV infection from other regions.

\section{TB treatment outcome at one year}

The TB treatment outcome was recorded for $75 \%$ of coinfected cases (79/106). Of these, 72\% (57/79) were known to have successfully completed their TB therapy within 12 months of their diagnosis, 16\% (13/79) did not complete treatment, $11 \%$ (9/79) were lost to follow-up or the outcome of TB therapy was recorded as unknown. The main reasons patients did not complete treatment within 12 months were either they were still on treatment (7/79) or had died (5/79). There were no statistically significant differences in successful treatment completion at one year between those with TB alone versus those with TB and HIV coinfection $(2,516 / 3,245 ; 77.5 \%$ treatment success for those with TB only).

The outcome of HIV treatment was not included in this study.

\section{Discussion}

This is the first national retrospective record linkage study to describe the characteristics and risk factors for TB and HIV coinfection in Scotland. Our results show there was a low incidence of TB and HIV coinfection in Scotland in the study period, with less than $3 \%$ of TB cases also having an HIV diagnosis. This is lower than the percentage of those tested with TB who were living with HIV reported in North America (8.3\%) but similar to the $3.5 \%$ reported in western and central Europe in 2012 [16] and to a seroprevalence study undertaken in Scotland in 1993 , in which less than $2 \%$ of notified TB cases tested positive for HIV [17].

Not all persons diagnosed with TB will accept an HIV test and there are undiagnosed HIV-positive individuals who would not be identified in this study. The results of our study indicate that the majority of coinfections are imported into the country by young migrant populations who have recently arrived in the UK from countries with high incidences of TB and HIV. The mean time from entry to the UK until TB diagnosis was statistically significantly lower for those with TB and HIV coinfections than those with TB alone (3.6 years vs 7.3 years). This is in contrast to that reported in the United States where the time to diagnosis was much longer and there were no statistically significant differences between TB and TB/HIV patients (14 years vs 13.1 years) [18] but similar to England and Wales where TB and HIV coinfection was more common in those who entered the UK in the five years or less before their TB diagnosis [19].

The majority of patients with TB and HIV coinfection presented with pulmonary disease, which is associated with a higher risk of transmission. Therefore there may be an increased risk of TB transmission to other high-risk contacts. 
The most common age group of those coinfected was 25-44 years, and the mean age was 37 years which is similar to that reported in England and Wales (34.7 years) [19]. TB and HIV coinfected individuals were almost nine years younger than those with TB infection alone, suggesting that HIV infection shortens the length of time to reactivate latent TB disease or that new infection is a more common cause of TB in HIVpositive patients than reactivation of latent TB [20].

Analysis of our study population showed that having TB and HIV coinfection was associated with having an increased likelihood of extra-thoracic lymph node involvement or cryptic/disseminated TB infection, which may be due to the effects of immunosuppression.

The majority of coinfected cases were of black African ethnicity, which is similar to that reported in England and Wales between 2002 and 2010, when $84 \%$ of heterosexual TB/HIV coinfections were in black Africans $[21,22]$. In our study, more than half of Black African patients were women but in all other ethnic groups, the majority were men. In Scotland, most coinfected individuals are reported to have acquired their HIV infection in Sub-Saharan Africa or south and south-east Asia, where they are more likely to have acquired their HIV infection via heterosexual intercourse. However, those born in the UK were more likely to be men who acquired their HIV infection through sex with other men.

Approximately one third of coinfected cases had an identified risk factor for TB, the most common of which was having refugee status, which was associated with an increased likelihood of TB and HIV coinfection. Most cases had received BCG vaccination and having a history of BCG vaccination was associated with an increased likelihood of having TB and HIV coinfection. This does not suggest that BCG vaccine is ineffective at preventing TB disease among HIV-infected individuals as BCG coverage may be higher in countries with a high incidence of TB. For some of the risk factors investigated, the number of coinfected cases was small and the findings need to be confirmed in larger studies.

ECDC recommends that information on TB outcome be known for $100 \%$ of cases and that $85 \%$ should successfully complete their TB treatment within 12 months [12]; the data from our study indicate that we have failed to meet these target levels, as the outcome of TB treatment was unknown for almost a third of cases. Therefore we cannot assess if optimum management of these cases resulted in successful treatment of TB therapy and this linkage study does not provide information on longer-term mortality among these patients.

\section{Conclusions}

Probabilistic data linkage was the most appropriate method for analysing TB and HIV coinfection in Scotland. TB and HIV coinfection was relatively uncommon in Scotland in the study period. Clinicians should recognise the potential for TB and HIV coinfection and the importance of prompting a HIV test for all TB cases, to ensure optimum management of coinfected patients and promote targeted prevention and control activities.

\section{Acknowledgments}

The authors would like to thank all the health professionals who support the TB and HIV surveillance systems.

\section{Conflict of interest}

None declared.

Authors' contributions

Eisin McDonald: study design, data analysis, manuscript; Lesley Wallace: study design, manuscript; Alison SmithPalmer: study design, manuscript; Oliver Blatchford: study design, manuscript.

\section{References}

1. Van den Broek J, Borgdorff MW, Pakker NG, Chum HJ, Klokke $\mathrm{AH}$, Senkoro KP, et al. HIV-1 infection as a risk factor for the development of tuberculosis: a case-control study in Tanzania. Int J Epidemiol. 1993;22(6):1159-65. http://dx.doi.org/10.1093/ ije/22.6.1159 PMID:8144300

2. World Health Organization (WHO). Global tuberculosis report 2013.,Geneva: WHO; 2013. Available from: http://apps.who. int/iris/bitstream/10665/91355/1/9789241564656_eng.pdf

3. Public Health etc. (Scotland) Act 2008. Edinburgh: The Scottish Parliament; 2008. Available from: http://www.legislation.gov. uk/asp/2008/5/pdfs/asp_20080005_en.pdf

4. Health Protection Scotland (HPS). Enhanced Surveillance of Mycobacterial Infections in Scotland (ESMI). Glasgow: HPS. [Accessed 1 Dec 2013]. Available from: http://www.hps.scot. nhs.uk/resp/ssdetail.aspx?id=15

5. McDonald E, Smith-Palmer A, Johnston F, Smith M, Laurenson IF, Donaghy M. Enhanced Surveillance of Mycobacterial Infections (ESMI) in Scotland: 2013 tuberculosis annual report for Scotland. HPS Weekly Report. 2013;47 No. 2013/44:385-94. Available from: http://www.documents.hps.scot.nhs.uk/ewr/ pdf2013/1344.pdf

6. Health Protection Scotland (HPS). New diagnosis of HIV and AIDS. Glasgow: HPS. [Accessed 1 Dec 2013]. Available from: http://www.hps.scot.nhs.uk/bbvsti/ssdetail.aspx?id=27

7. Health Protection Scotland (HPS). Trends in HIV reporting, Scotland by selected year of report; to 31 December 2011. Glasgow: HPS; Apr 2012. Available from: http://www. documents.hps.scot.nhs.uk/bbvsti/annual-data-tables/2011/ hiv-trends-scotland-2011.pdf

8. Health Protection Network. Tuberculosis: Clinical diagnosis and management of tuberculosis, and measures for its prevention and control in Scotland. Health Protection Network Scottish Guidance 5. Glasgow: Health Protection Scotland; 2009. Available from: http://www.documents.hps.scot.nhs.uk/ about-hps/hpn/tuberculosis-guidelines.pdf

9. National Institute for Health and Clinical Excellence (NICE) Tuberculosis: Clinical diagnosis and management of tuberculosis, and measures for its prevention and control. London: NICE; 2011. Available from: http://www.ncbi.nlm.nih. gov/pubmedhealth/PMHoo46822/pdf/TOC.pdf

10. British HIV Association (BHIVA), British Association for Sexual Health and HIV (BASHH) and British Infection Society (BIS). UK National Guidelines for HIV testing 2008. London, Macclesfield, Knutsford: BHIVA, BASHH, BIS; 2008. Available from: http://www.bhiva.org/documents/guidelines/testing/ glineshivtesto8.pdf

11. A TB action plan for Scotland. Edinburgh: The Scottish Government; 2011. Available from: http://www.gov.scot/ resource/doc/346224/0115224.pdf

12. European Centre for Disease Prevention and Control (ECDC). Progressing towards TB elimination. Stockholm: ECDC; 2010. Available from: http://ecdc.europa.eu/en/publications/ 
Publications/101111_SPR_Progressing_towards_TB_ elimination.pdf

13. United States National Archives and Records Administration (NARA). The Soundex Indexing System. Washington, DC: NARA. [Accessed 28 Aug 2013]. Available from: http://www.archives. gov/research/census/soundex.html

14. Fellegi IP, Sunter AB. A theory for record linkage. J Am Stat Assoc. 1969;64(328):1183-210. http://dx.doi.org/10.1080/0162 1459.1969.10501049

15. Kendrick S, Clarke J. The Scottish record linkage system. Health Bull (Edinb). 1993;51(2):72-9. PMID:8514493

16. Joint United Nations Programme on HIV/AIDS (UNAIDS). Global report: UNAIDS report on the global AIDS epidemic 2012. Geneva: UNAIDS; 2012. Available from: http://www.unaids. org/sites/default/files/en/media/unaids/contentassets/ documents/epidemiology/2012/gr2012/20121120_UNAIDS_ Global Report_2012 with_annexes_en.pdf

17. Leitch AG, Rubilar M, Curnow J, Boyd G, Forbes GI, Burns S, et al. Scottish national survey of tuberculosis notifications 1993 with special reference to the prevalence of HIV seropositivity. Thorax. 1996;51(1):78-81. http://dx.doi.org/10.1136/thx.51.1.78 PMID:8658375

18. Rodwell TC, Barnes RFW, Moore M, Strathdee SA, Raich A, Moser KS, et al. HIV-tuberculosis coinfection in Southern California: evaluating disparities in disease burden. Am J Public Health. 2010;100(S1) Suppl 1;S178-85. http://dx.doi. org/10.2105/AJPH.2009.170142 PMID:20147681

19. Rice B, Elford J, Yin Z, Kruijshaar M, Abubakar I, Lipman $M$, et al. Decreasing incidence of tuberculosis among heterosexuals living with diagnosed HIV in England and Wales. AIDS. 2013;27(7):1151-7. http://dx.doi.org/10.1097/ QAD.obo13e32835e2cb1 PMID:23276802

20. Leitch AG, Rubilar M, Watt B, Laing R, Willcocks L, Brettle RP, et al. Why disease due to Mycobacterium tuberculosis is less common than expected in HIV-positive patients in Edinburgh. Respir Med. 1995;89(7):495-7. http://dx.doi.org/10.1016/09546111(95)90125-6 PMID:7480979

21. Ahmed AB, Abubakar I, Delpech V, Lipman M, Boccia D, Forde J, et al. The growing impact of HIV infection on the epidemiology of tuberculosis in England and Wales: 1999 2003. Thorax. 2007;62(8):672-6. http://dx.doi.org/10.1136/thx.2006.072611 PMID:17311840

22. Grant AD, Bansi L, Ainsworth J, Anderson J, Delpech V, Easterbrook $P$, et al.. Tuberculosis among people with HIV infection in the United Kingdom: opportunities for prevention? AIDS. 2009;23(18):2507-15. http://dx.doi.org/10.1097/ QAD.obo13e3283320dfd PMID:19770622 